\section{UTOPÍAS DICOTÓMICAS SOBRE LOS CUERPOS SEXUADOS}

\author{
Nuria Gregori Flor \\ U. de Valencia. Instituto de Filosofía (CSIC). Hospital d'Elx \\ interemergen@gmail.com
}

\section{DICHOTOMIC UTOPIES ON SEXED BODIES}

Cómo citar este artículo/Citation: Gregori Flor, N. (2013). "Utopías dicotómicas sobre los cuerpos sexuados". Arbor, 189 (763): a071. doi: http://dx.doi.org/10.3989/ arbor.2013.763n3008

Recibido: 13 julio 2012. Aceptado: 6 junio 2013.

RESUMEN: Hermafroditas, intersexos, andróginos, transexuales u homosexuales simbolizan el lugar de la fisura, de la frontera, de la disidencia en relación a los cuerpos sexuados, los géneros y las sexualidades. Constituyen a su vez un espacio discursivo privilegiado desde donde recorrer algunas de las certezas que se han ido produciendo y reproduciendo desde los distintos campos de conocimiento y poder a lo largo de la historia de Occidente. El análisis de categorías médico-sociales como el "hermafroditismo", la "intersexualidad", o la más recientemente conocida como "DSD/ADS", nos descubre un panorama complejo y a la vez controvertido, pero con el potencial suficiente para indagar en el carácter performativo de las categorías sociales. Además, nos permite adentrarnos en un debate bioético más amplio sobre los límites de las prácticas médicas, las cuestiones relativas al control y la normalización de cuerpos, o sobre la incorporación de nuevas tecnologías en la conformación de cuerpos e identidades.

PALABRAS CLAVE: Hermafroditismos; Intersexualidad; Disorders of Sex Development (DSD)/Anomalías de la diferenciación sexual (ADS); Diferenciación Sexual Atípica (DSA); Sexos/Géneros/Sexualidades.
Copyright: (C) 2013 CSIC. Este es un artículo de acceso abierto distribuido bajo los términos de la licencia Creative Commons Attribution-Non Commercial (by-nc) Spain 3.0.

ABSTRACT: Hermaphrodites, intersexes, androgynes, transsexuals and homosexuals symbolise the place of the fissure, the border and dissent in relation to bodies and sexes/genders/ sexualities. They represent a privileged discursive space from where we can explore some of the certainties that have been produced and reproduced from the different fields of knowledge and power throughout Western history. The analysis of social and medical categories such as hermaphroditism, intersexuality, or the recently known as DSD shows us a complex and simultaneously controversial panorama that has, nevertheless, enough potential to shed some light on the performative role of social categories. Moreover, it allows us to go into a bioethical debate about the limits of medical practices, and to explore questions about the body's control and normalisation, or about the incorporation of new technologies in recreating bodies and identities.

KEYWORDS: Hermaphroditism; Intersexuality; Disorders of Sexual Development (DSD); Atypical Sexual Differentiation (ASD); Sex/Gender/Sexualities. 


\section{INTRODUCCIÓN}

Al acercarnos al territorio fronterizo del sexo, son muchas las señales que nos indican la dirección correcta a seguir. Muchas señales hacia opciones que, sin embargo, son más bien escasas. Uno de los casos mediáticos que podría introducir la discusión sobre los estrechos y sospechosos márgenes de ese confín conocido como "sexo", sería el de la atleta sudafricana Caster Semenya, medalla de oro en los mundiales de Berlín en los 800 metros. Semenya, al igual que otras deportistas de élite como Santhi Soundarajan (El Mundo, 2006; El País, 2006) y María José Martínez Patiño (Fausto-Sterling, 2006), encarna una verdad que desestabiliza y pone en cuestión uno de los grandes pilares de la sociedad occidental: el "dimorfismo sexual", o la creencia en dos únicas posibilidades corporales sexuadas que se corresponden con identidades y deseos concretos.

Quizás una apariencia musculada y robusta, una voz grave y dos segundos de ventaja frente a su rival inmediata, le bastaron a la IAAF (Federación Internacional de Atletismo) para someter a Semenya a las pruebas conocidas como "tests de género o de feminidad"1 tras su victoria. En ellos se desvelarían cromosomas $\mathrm{XY}$, ausencia de útero y ovarios, posibles testículos en el interior del abdomen y niveles de testosterona superiores a los esperados (Hurst, 2009). Estos parámetros biológicos serían prueba suficiente para justificar la superioridad de Semenya respecto a sus compañeras, para retirarle la medalla y para suspenderla de la competición. La autoridad científica anulaba automáticamente la voluntad y la subjetividad de la atleta, redefiniendo su identidad de género en base a resultados de laboratorio (Ginnane, 2011). Mientras tanto, y a pesar de que la deportista manifestara abiertamente y en repetidas ocasiones que ella era una mujer, la prensa internacional se disputaba la exclusiva ${ }^{2}$, y Sudáfrica, indignada, la llevaba a la primera página de su revista You (2009) vestida con un vaporoso traje de noche, mucho maquillaje, extensiones de pelo y de uñas, bisutería y zapatos de tacón, para demostrar al mundo que Semenya era una verdadera mujer. ${ }^{3}$

El caso de Semenya muestra el imponente artefacto social y cultural que divide la humanidad en dos mitades y en dos únicas posibilidades de ser y estar en el mundo, construyendo dualidades excluyentes y complementarias. El cuerpo de Semenya, el de Soundara$j^{4}{ }^{4}$, el de Martínez Patiño o el de cualquier persona con una "diferenciación sexual atípica" (DSA) constituye un espacio discursivo privilegiado desde donde podemos recorrer algunas de las certezas que se han ido produciendo y reproduciendo en los distintos campos de conocimiento y de poder a lo largo de la historia de Occidente. Un lugar estratégico desde donde contemplar y cuestionar los movimientos sociales, legales y médicos que nos han constituido como hombres, como mujeres, o como todo lo contrario. ¿Cuáles han sido esas verdades dictadas sobre los sexos? ¿Quiénes han sido legitimados para nombrarlas?

\section{“HERMAFRODITISMOS” E “INTERSEXOS” EN LA CONSTRUCCIÓN DE LA DIFERENCIA SEXUAL}

Para deconstruir la diferencia sexual será necesario que nos movamos entre los diferentes "regímenes de verdad" que a lo largo de la historia han ido produciendo categorías y respuestas alrededor de los sexos, las sexualidades y las relaciones de género. Supone atender a las más variopintas explicaciones sobre qué y cómo se determina el sexo, cómo se produce la diferencia sexual, cómo se materializa el género en los cuerpos, o cuáles han sido las diferentes desviaciones de la norma sexuada.

La historia de la "desviación sexual" - anatómica, fisiológica, psicológica y/o social- respecto a las normas vigentes en nuestro contexto occidental europeo, ha manejado una amalgama de categorías que se han ido superponiendo e intercalando a lo largo del tiempo. En la actualidad nos parece clara la separación y la distinción entre las que se refieren a la identidad sexual o de género - "transexualidad"-, las que responden al deseo - "heterosexualidad/homosexualidad" - o las que hablan de la anatomía sexual y su funcionamiento - "intersexualidad"- Pero si contemplamos estas categorías desde un punto de vista histórico, comprobamos que términos como el de "travestismo", "intersexualidad", "homosexualidad", "sexo cromosómico", "hipospadias" o "pseudohermafroditismo" se confunden y solapan.

De la misma forma que ha mudado el abanico de situaciones y de personas incluidas bajo el paraguas de estas categorías, también lo ha hecho el trato/tratamiento médico y social que las mismas han recibido. Así, por ejemplo, el periodo histórico comprendido entre el siglo XIX y principios del XX fue una etapa de gran preocupación por las "perversiones sexuales" y de cierta obsesión por el hermafroditismo. Durante este periodo la medicina y la psicología armonizaron con lo que se entendía como falta de correspondencia entre sexo biológico, cuerpos y prácticas sexuales. El término "hermafrodita" no era utilizado específicamente para referirse a personas que nacían con unos genitales inusuales, sino que se consideraban 
hermafroditas aquellas personas que hoy son clasificadas como travestidas, transexuales, homosexuales o feministas (Dreger, 1998a; De Gabriel, 2010). De la misma manera, veremos cómo lo que en la España de los años 30 se consideraba una forma de intersexualidad, en los años 60 se asoció con la homosexualidad.

De hecho, incluso términos que actualmente solo nos remiten a una DSA, como "hermafroditismos", "pseudohermafroditismos", "hipospadias", "estados intersexuales", o los recientemente acuñados "DSD (Disorders of Sex Development)/ADS (Anomalías de la Diferenciación Sexual)" (Lee et al., 2006), también encierran significados y fronteras distintas en función del periodo histórico. Así, los "vicios de conformación" ${ }^{\prime 6}$ que en la España de 1905-1915 se hicieron Ilamar "hipospadias", una década después perdieron vigencia para volver a catalogarse bajo alguna forma de "pseudohermafroditismo". Efectivamente, comprobamos cómo las categorías de las "intersexualidades/ ADS" de las que parte este trabajo no tienen mucho que ver con las que planteaba Marañón en sus exitosas teorías de los años 30. Para el "Darwin español"7, los "varones criptórquidos e hipospádicos, las mujeres hirsutas y aquejadas de insuficiencia ovárica, los hermafroditas con ovotestis, andróginos y ginandros, eunucos y eunucoides, ginecomastas, mujeres viriloides, homosexuales y un sinfín de personajes quedarían clasificados en el vasto espectro de los estados intersexuales" (Vázquez y Cleminson, 2011, 185).

Pero, ¿a qué se debe este afán por nombrar y renombrar lo que se escapa a la norma? ¿Qué intereses esconden tan exhaustivas clasificaciones? Cualquier incumplimiento de la "norma sexuada" - ya sea en la apariencia, en los roles, en los deseos o en las prácticas sexuales - ha sido sistemáticamente clasificado y vigilado, para a continuación poder ser disciplinado e incluso borrado por las agencias expertas. Tal y como apreciaría Alice Dreger (1998a), el hermafroditismo provocó más confusión de lo que pudiera parecer, porque - como veremos una y otra vez- el descubrimiento del cuerpo "hermafrodita", elevó dudas no solo sobre un cuerpo particular, sino sobre todos los cuerpos. En este sentido nos parece interesante recrear -en el sentido de "iteración" de Judith Butler (2002) - , cuáles han sido y son las fronteras definidas para los cuerpos sexuados, sus medidas, sus formas y sus funciones; las instituciones socialmente legitimadas en cada momento y lugar para dictar lo que es "normal" y "anormal" en relación a los sexos/géneros y a las sexualidades; cómo esas fronteras han definido y organizado el modelo de vida sexual que preconce- bían como sano y equilibrado; así como las etiquetas, definiciones y percepción social que se han generado y otorgado a esos márgenes.

\section{De la elección del "sexo estamental" a la invención de la "monosexualidad"}

El término "hermafroditismo" es el más antiguo que encontramos para referir la anatomía sexual atípica y el primero que empezó a utilizar la biomedicina (Dreger, 1998a; Reis, 2009). Exótico, monstruoso, temido e incluso deseado, el cuerpo hermafrodita alertaba de una existencia sexuada más allá de los márgenes previstos. Una existencia peligrosa que debería ser controlada para no poner en peligro el orden moral de la época.

Sin embargo, durante el periodo medieval, el "hermafroditismo" era posible. Esta posibilidad quedó inscrita tanto en las teorías sobre la diferencia sexual como en las prácticas administrativas y legales. Precisamente, en la representación de la teoría medieval de la generación, la matriz quedaba escindida en tres cavidades y el acto generador consistía en una pugna entre los sémenes del macho y de la hembra. Si el semen masculino vencía en el torneo, cayendo en la cavidad de la derecha, se engendraría un niño de rasgos viriles. Si el semen femenino se declaraba victorioso y se derramaba en el mismo lugar, se obtendría un varón afeminado. Una argumentación análoga pero referida a la cavidad izquierda explicaba la generación de hembras. El "hermafrodita" era resultado de una justa indecisa, por la cual los sémenes se mezclaban en la cavidad central de la matriz (Laqueur, 1994). En este sentido, el "hermafrodita" era una posibilidad dentro del "orden natural" de los seres.

Foucault (1985) dirá que en la Edad Media se aceptaba la existencia hermafrodita, pero solo bajo la consideración de seres o "monstruos" con los dos sexos sobre los cuales recaía todo un dispositivo legal y médico. Pero reconocer la existencia de ambos sexos en el mismo individuo, no significaba la aceptación social de un "tercer género" como pudiera ocurrir en otras culturas con mayor "variancia" de género. Esa persona con los dos sexos debía optar por uno, el "sexo determinado" (Vázquez y Moreno, 1995), y cumplir con ciertos preceptos como la fijación de la identidad en el bautismo, en el matrimonio, en las sucesiones hereditarias, en la testificación ante los tribunales, en la unción sacerdotal y en la interdicción de la sodomía (ibíd.).

Concretamente, las reglas del derecho canónico y civil regulaban cómo en estas situaciones el padre o 
el padrino debían ser los encargados de determinar, en el momento del bautismo, el sexo que iba a mantenerse en la persona. Sin embargo, en la edad adulta, cuando se aproximaba el momento de casarse, el "hermafrodita" era libre de decidir por sí mismo si quería continuar siendo del sexo que se le había atribuido o prefería el otro. La única condición impuesta era la de no cambiar nunca más y mantener hasta el fin de sus días lo que entonces había declarado, bajo pena de sodomía (Foucault, 1985). Según Vázquez y Moreno $(1995,99)$, la hechura monstruosa, excluida del cuadro de los sacramentos, era purificada en el hermafrodita por el acto de escoger un "sexo determinado" a través de la imposición de nombre. En definitiva, "la verdad del cuerpo y de su existencia no derivaba de una exégesis médica: era el efecto perlocucionario de una ceremonia de elección y juramento (antes de casarse el individuo se comprometía a continuar con el sexo escogido hasta el final de sus días)" (ibíd.). Nos hallamos ante un régimen de verdad que no era médico, sino el efecto de una ceremonia de elección y juramente, es decir, una decisión social-legal.

A pesar de esta aparente flexibilidad, el cuerpo hermafrodita seguía representando un peligro frente al orden social imperante, ya que de alguna forma poseía el potencial para materializar conductas sexuales aberrantes. Porque, tal y como Foucault $(1985,14)$ enunciara, "las fantasmagorías de la naturaleza pueden promover los extravíos del libertinaje", y lo "anormal" en el orden de lo biológico anunciaría el desorden social. Pero la gestión "social" de este potencial desorden no tardaría en ceder su sitio a un "nuevo orden de jurisprudencia exclusivamente médica" que proscribía la duplicidad sexual en nombre del "sexo verdadero" (Vázquez y Moreno, 1985).

\section{La naturalización del "monstruo" por la teratología y el desarrollo de la medicina legal}

El nuevo estado liberal de principios del siglo XIX ya no definía la identidad social de los individuos por su nombre y sus relaciones externas, sino a partir de su "interioridad". Entramos de lleno en la era de una "racionalidad biotécnica" que desplaza al derecho y que se superpone a la autoridad jurídica para decidir acerca de la identidad de los sujetos (Vázquez y Moreno, 1995, 109). Pero este proceso requería la introducción del monstruo en la ciencia teratológica y en el mundo natural de las cosas. Existían dos sexos, y bajo esa aparente duplicidad de los sexos, solo podía haber malformaciones genitales más o menos monstruosas.

La "racionalidad biotécnica" va a llegar acompañada de nuevos agentes sociales definidos por su capa- cidad "experta", es decir, con capacidades específicas para leer la interioridad. Hablamos de un periodo que coincide con el desarrollo de la medicina legal y en el que destacan las ideas del cirujano Plenck (1796), que desarrolló los cinco problemas importantes que planteaba el hermafroditismo: el nombre con el que bautizar a los niños; la legitimidad de los matrimonios, que solo eran posibles entre un hombre y una mujer; la determinación del sexo de los esposos si ambos son hermafroditas; la licencia para realizar ocupaciones de hombre o mujer o la clase de vestimenta que debería llevar (Vázquez y Cleminson, 2010).

\section{La expulsión del "hermafrodita" y la consolidación del "dimorfismo sexual"}

La conciencia pública general de los cuerpos hermafroditas se fue desvaneciendo lentamente en las sociedades occidentales europeas en la medida en que la medicina se apropió gradualmente de la autoridad para interpretar - y gestionar - la categoría que con anterioridad había sido conocida ampliamente como "hermafroditismo" (Dreger, en Chase, 2005:88). Resumiendo, la desaparición de la categoría del "hermafroditismo verdadero" coincidirá con el asentamiento del modelo de los "dos sexos" desarrollado por Laqueur (1994). En la medida en que ya no es posible la existencia de dos sexos en un mismo individuo, desaparece el mito de los tres sexos posibles: "A cada uno su identidad sexual primera, profunda, determinada y determinante; los elementos del otro sexo que puedan aparecer tienen que ser accidentales, superficiales 0 , incluso, simplemente ilusorios" (Foucault, 1985, 13).

Son varios los factores que precipitaron el cambio de paradigma que venimos describiendo: por una parte, el crecimiento del sector médico y de sus especialistas (especialmente ginecólogos), con el progresivo aumento de la población medicalizada y la implantación de un "régimen biomédico de la vida" (cada vez más personas consultaban al médico); por otra, el aumento de la ansiedad social ante la recién etiquetada homosexualidad y ante la agitación de un número de mujeres cada vez mayor reclamando igualdad de derechos en sus profesiones y universidades. Estas aspiraciones de cambio en los roles de género contribuyeron sin duda a que los estamentos de poder se esforzaran por detectar "anomalías" en quienes no ocupaban el lugar previsto para ellos.

No es casual la efervescencia de trabajos que en este periodo indagaban aspectos relacionados con el sexo, la sexualidad y las recién estrenadas identida- 
des político-sexuales. El proyecto modernizador de finales de siglo XIX protegía a los ciudadanos "normales" y clasificaba a los que no lo eran: es decir, a los locos, los degenerados, los perversos, los anormales o los iluminados. Ello significaba "inmovilidad, fijación, control, vigilancia, territorialización del espacio, archivos de las identidades, de los pensamientos, de las tentaciones utópicas" (Cleminson y Medina, 2004, 15). El conocimiento biomédico fue configurándose como brazo ejecutor del orden imperante, clasificando, fijando y normativizando las identidades sexuales en una irrefrenable carrera hacia una hiperespecialización e hipercategorización en cuestiones de sexo/ género. Cleminson y Medina (2004) entienden esta categorización progresiva, basada en la construcción de diferencias entre sexos y géneros, como el lugar de racionalización de la desigualdad mediante su naturalización y su corporeización. Dentro de este orden, la conducta hermafrodita se va a vincular a la "peligrosidad sexual".

Para Dreger (1998a), esa ansiedad y la inestabilidad propia de este periodo se resuelven en lo que ella rotuló como la "definición gonadal del sexo". La difusión de la clasificación del "sistema de Klebs" ${ }^{8}$ a finales del siglo XIX marcará un punto de inflexión en este proceso de tecnificación y especialización del sexo, así como en las bases para asignar el sexo verdadero y definitivo en las personas. Este momento histórico forma parte de lo que Dreger (1998a) denominó "la edad de las gónadas" ${ }^{\prime \prime}$, es decir, la jurisdicción médica dedicada a la determinación del verdadero y único sexo sobre la base del criterio gonadal. Dentro de este paradigma, el "sexo verdadero" no se basaba en características como la voz, el andar, la idoneidad para la cópula o el tamaño del pene o del clítoris, sino que se basaba en la existencia de gónadas sexuales que se suponían la clave corpórea de la fecundidad y la reproducción, por tanto, de la identidad de sexo de la persona (Cleminson y Medina, 2004, 25). La creencia médica en esta definición del sexo gonadal fue tan fuerte que "en la Inglaterra del momento el "problema" de una mujer con testículos fue resuelto en ocasiones extirpándole los testículos, mientras que en Francia se imploraba a esos pacientes que abandonaran sus uniones "homosexuales" con hombres" (Dreger, 1998a, 9).

En este nuevo saber, el "hermafrodita" como figura engañosa, era sustituido por el "pseudohermafrodita". El "sexo verdadero" del pseudohermafrodita se escondía en su interior, invisible a la mirada inexperta. Dentro de este esquema, tanto los rasgos físicos como los psíquicos considerados monstruosos en el pasado, cambiaban la consideración social para pasar a ser "anomalías", "alteraciones" o "trastornos".

Las memorias de Herculine Barbin, encontradas en el apartamento de París donde se suicidó en 1868, dejan constancia de este periodo de apropiación progresiva sobre los cuerpos sexuados por parte de la medicina. Alexina Herculine Barbin, educada como mujer según los cánones típicos de la época y dedicada a la docencia en un internado de mujeres, fue reasignada ${ }^{10}$ como hombre tras visitar a un médico por dolores abdominales y descubrirse que poseía unos testículos en proceso de descenso y un clítoris demasiado grande como para ser considerado como tal.

No obstante, tanto Medina, como Cleminson y Vázquez expondrán cómo la conocida como "edad de las gónadas", en España tuvo que competir con un nuevo estilo de pensamiento introducido hacia 1913: las hormonas invocadas como responsables últimas de la identidad sexual del individuo. La edad de las gónadas abría un periodo que remitía a la materialidad del sexo, "una cosa, las gónadas"; pero al entrar en la era de las secreciones internas, se producía un proceso de fractura biológica y química, "la diferenciación sexual producida por la compleja dinámica de las secreciones internas" (Vázquez y Cleminson, 2011, 181).

Fausto-Sterling (2006) diferencia la "edad de las gónadas", empeñada en la búsqueda del "verdadero sexo", y la "edad de la conversión", empeñada en eliminar a la gente nacida con sexo mixto para transformarla en varones o mujeres. En España encontramos dos figuras que marcan ese punto de inflexión hacia la "edad de la conversión": el endocrinólogo Gregorio Marañón y el ginecólogo José Botella Lusiá. Ambos rompieron con el canon médico del momento respecto a las concepciones de sexo/género y dispusieron las bases del actual modelo de abordaje médico en situaciones intersexuales.

Para el endocrinólogo la diferencia entre sexos se establecería como una escala de gradaciones dentro de la cual nos situamos la mayoría de nosotros:

"Casi ningún humano presenta los signos sexuales en toda su pureza (...) la observación minuciosa descubrirá, casi sin excepción, la huella del "otro sexo", que perdura en un grupo de rasgos, morfológicos (la distribución del vello y del cabello, el desarrollo de la laringe, las proporciones del esqueleto, etc.) o funcionales (libido, conducta social, carácter, sensibilidad, voz, etc.)" (Marañón, 1930, 259).

Pero lo que en apariencia pudiera parecer en Marañón un modelo de apertura y de ruptura de los clási- 
cos dualismos, una mirada más profunda nos descubrirá que su idea de "continuo" no tenía otra utilidad que la de identificar problemas dentro de esa escala de gradaciones. En realidad, esta descripción del sexo más "fluida" le va a servir como base teórica para la posterior definición de las "desviaciones", los "defectos", las "anomalías" o los diferentes "problemas" que se establecen en la diferenciación sexual y que en definitiva originan lo que el nombró como "estados intersexuales". Los diversos estados intersexuales serían entonces el resultado de perturbaciones en la acción del sistema glandular" (ibíd.). En concreto, Marañón entiende por estados intersexuales "aquellos casos en que coinciden en un mismo individuo - sea hombre, sea mujer - estigmas físicos o funcionales de los dos sexos; ya mezclados en proporciones equivalentes o casi equivalentes; ya, y esto es mucho más frecuente, con indiscutible predominio del sexo legítimo sobre el espúreo" (Marañón, 1930, 4).

El colofón de las teorías del endocrinólogo culminaba en una detallada clasificación de las intersexualidades en dos grandes grupos: las "intersexualidades permanentes" y las "intersexualidades transitorias". Dentro de las primeras incluyó la "homosexualidad", el "travestismo" y la "transexualidad". Entre las que denominó "intersexualidades transitorias", encontramos las "intersexualidades gravídicas"11, la "homosexualidad episódica" en los hombres ${ }^{12}$ y las bautizadas por él como "intersexualidades críticas", es decir, la "intersexualidad feminoide en los hombres púberes"13, la "intersexualidad viriloide en el climaterio y en la vejez"14, etc. En esta clasificación descubrimos que la concepción marañoniana de intersexualidad incluía cualquier grado de incumplimiento de la norma sexuada en cuanto a aspecto físico, roles, prácticas sexuales, y/o deseos y expectativas (Marañón, 1928).

En la medida en que se fueron desarrollando nuevas categorías nosológicas y otras sofisticadas clasificaciones, el criterio para definir y determinar el sexo también se tornaba más complejo, difuso e imposible de concretar sin el uso de las más avanzadas tecnologías de diagnóstico. Teresa de Lauretis (1989) llega a la conclusión de que las tecnologías médicas empleadas - tanto materiales como discursivas - contribuyeron a la configuración de un conocimiento médico que producía -y hacía posible con su repetición-, ciertas concepciones fijas acerca del sexo y de lo que nosotros ahora definiríamos como género. En la misma línea, Laqueur (1994) matizaba cómo ese perfeccionamiento tecnológico, cada vez más preciso para definir y clasificar el sexo, no ha significado cambios en las concepciones y en la construcción social del sexo/género/sexualidades:

\begin{abstract}
"Ningún descubrimiento singular o grupo de descubrimientos provocó el nacimiento del modelo de dos sexos, precisamente por las mismas razones que los descubrimientos anatómicos del Renacimiento no desplazaron al modelo unisexo: la naturaleza de la diferencia sexual no es susceptible de comprobación empírica. Es lógicamente independiente de los hechos biológicos, porque una vez incorporados éstos al lenguaje de la ciencia constituyen también el lenguaje del género, al menos cuando se aplican a una interpretación culturalmente importante de la diferencia sexual. En otras palabras, casi todas las afirmaciones relativas al sexo están cargadas desde el principio con la repercusión cultural de las mismas propuestas. Pese al nuevo estatus epistemológico de la naturaleza como sustrato de las distinciones y pese a la acumulación de hechos sobre el sexo, la diferencia sexual no fue más estable en los siglos que siguieron a la revolución científica de lo que antes había sido. Dos sexos inconmensurables eran, y son, productos culturales, en la misma medida que lo era, y es, el modelo unisexo ${ }^{15}$." (Laqueur, 1994, 265).
\end{abstract}

De hecho, Vázquez y Cleminson (2011) recordarán cómo la batalla por definir los límites del hermafroditismo que tuvo lugar en España en el primer tercio del siglo XX, no solo fue resultado de la teoría marañoniana de la intersexualidad, sino que, como ya hemos avanzado, fue consecuencia de un proceso de definición de los sexos mucho más vasto en el que algunos médicos y comentaristas sociales quisieron reafirmar la diferencia entre los sexos, a la luz de lo que comúnmente se percibía como "un confusionismo de los géneros auspiciado por las feministas" (p. 128).

Nuestra actualizada construcción del sexo, avalada por la tecnología y por la férrea creencia en la neutralidad y la objetividad científica, acabará configurándose como una de las estrategias más efectivas para hacer pervivir la creencia en dos únicas posibilidades de cuerpos, con sus correspondientes identidades y roles de género. En esta construcción, el conocido como "sexo" combina una serie de parámetros biológicos de lo que podríamos reconocer como el "cuerpo visible" y el "cuerpo no visible". Ese "cuerpo visible" se relaciona con la apariencia corporal externa, es decir, la distribución de la grasa y del vello, la estructura ósea y muscular, así como el aspecto de los genitales externos. El "cuerpo no visible" representa todos aquellos resultados de laboratorio o de exámenes radiológicos producto de tecnologías médicas, es decir, gónadas, cromosomas, hormonas, enzimas o cadenas de genes. Se trata de una micro-corporalidad inteligible únicamente para un reducido grupo de iniciados 
en leer e interpretar resultados de laboratorio, ecografías o escáneres. El resultado de "hombre" o "mujer" no es más que el cumplimiento de un esquema de coherencia entre todos estos parámetros biológicos propuestos por la biomedicina. El hombre y la mujer son el resultado de lo que se entiende por una "diferenciación" y un "desarrollo sexual normal".

La "incoherencia" se paga con medicalización. Una medicalización violenta en la que las tecnologías médicas - fármacos, hormonas y cirugía - modelan un sexo que "simula" la dualidad perfecta, sin fisuras. La concepción de "sexo verdadero" se transformaba, gracias a las tecnologías médicas, en una de "sexo conveniente o simulacro" (Cleminson y Vázquez, 2011). Cualquier desajuste o falta de correspondencia a partir de este constructo, conduce irremediablemente hacia la lista de los no aptos, es decir, aquellos que deberán ser nombrados, controlados y corregidos.

\section{PROTOCOLOS, PRÁCTICAS Y TECNOLOGÍAS DE “NOR- MALIZACIÓN" DEL SEXO}

El proceso de superespecialización y superdiferenciación médica, unido a la aparición de las teorías que en los años 50 distinguieron entre "sexo biológico" y "género psicosocial" (Money y Ehrhardt, 1972; en Cleminson y Medina, 2004, 25), conforman el paradigma contemporáneo en el diagnóstico y tratamiento médico de la DSA. Para Suzanne Kessler casi toda la literatura publicada sobre el manejo de casos de niños intersexuales habría sido escrita o co-escrita por un solo investigador: John Money (en Kipnis y Diamond, 1999). El famoso y polémico pediatra endocrinólogo diseñó en 1952 unos protocolos para determinar el sexo en recién nacidos con genitales ambiguos. A partir del experimento que le valió la fama con los gemelos John/Joan (Money y Ehrhardt, 1972; Money, 1973; Colapinto, 2001), Money desarrolló una teoría en la que defendía que la identidad de género es neutral en el nacimiento y en la infancia temprana - hasta los dos años-, determinándose posteriormente por los genitales y la crianza. Es decir, que la identidad de género sería exclusivamente el producto de la educación y la socialización. Según esta teoría, la mente del niño sería como una pizarra en blanco ausente de características inherentes de personalidad. Un poco más tarde, en los años 60, los avances de la cirugía plástica combinados con esta teoría de "Genitales + Crianza = identidad de género", aportaron una racionalización teórica que condujo a los médicos a recomendar la cirugía "correctiva" en recién nacidos con condiciones intersexuales. La idea era que una vez fuera asignado médicamente el sexo del bebé, se reconstruyeran los genitales para que se vieran estéticamente correctos, ya fuera de niño o de niña, y luego criarlo en su correspondiente género, con la convicción de que crecería con esa misma identidad de género (Money, Hampson y Hampson, 1955; Dreger, 1998a; Fausto-Sterling, 2006; Reis, 2009; Gregori, 2008).

Sin embargo, con la difusión años más tarde del fracaso del ensayo con los gemelos John/Joan de mano de sus detractores, el biólogo Milton Diamond y el psiquiatra Keith Sigmundson (Diamond y Sigmundson, 1977; William y Smith, 1980), y junto con la "teoría biosocial de la interacción" de Diamond ${ }^{16}$ (1965, 1968), se abría una nueva etapa en la cual se volvía a reforzar la idea de un género anterior al cuerpo. Esto significaba una vuelta a la creencia en una identidad de género, mujer o varón, presocial, biológicamente determinada, y marcada neurológicamente y en el cerebro durante el periodo embrionario y fetal.

Si revisamos la literatura existente en el contexto español, la versión española del "sexo conveniente o sexo simulacro" de John Money se materializa en el ginecólogo José Botella Llusiá. Según sugieren Vázquez y Cleminson (2011), los criterios que propuso BoteIla eran muy afines a las pautas que recomendaba y aplicaba la comunidad médica internacional entre los años 50 y 60. Aun así, conviene recordar que al tiempo que Money exponía sus teorías y experimentos, en España todavía vivíamos las consecuencias de un tardofranquismo que sin duda tendría una influencia decisiva en la consideración de la intersexualidad (ibíd.).

Desafortunadamente no hemos podido encontrar un trabajo exhaustivo que recoja las bases epistemológicas y las prácticas clínicas acerca de la intersexualidad en nuestro país y que comprenda el periodo histórico desde el inicio de la democracia hasta el momento actual. Ante este vacío, el análisis que exponemos a continuación avanza algunos resultados del trabajo de campo que venimos realizando desde el 2004 hasta la actualidad ${ }^{17}$, junto con las referencias bibliográficas que manejan hoy los equipos de expertos médicos españoles, ya sean desde investigaciones propias de su experiencia clínica o desde fuentes o consensos internacionales.

\section{Cuando "hay que" asignar uno de los dos sexos}

Tanto en la bibliografía revisada de los diez últimos años como en lo expresado en cada entrevista o encuentro personal con expertos médicos españoles, se repiten los mismos parámetros a considerar a la hora 
de decidir el sexo a asignar a un recién nacido con una DSA. Estos son: la genética, la anatomía, la funcionalidad, los resultados endocrinológicos, la opinión de los cirujanos en cuanto a posibilidades de reconstrucción anatómica, la decisión de los padres y las experiencias en casos anteriores ${ }^{18}$. Aunque parezcan muchos los elementos a tener en cuenta, realmente los podríamos resumir en tres factores decisivos: La "probable identidad de género futura", la "potencial fertilidad" y la "capacidad funcional de los genitales externos".

Merece la pena detenernos por un momento en los entresijos de estas decisiones, por las implicaciones personales y políticas que contienen. Por un lado comprobaremos los presupuestos o expectativas culturales - sobre los cuerpos, los sexos/géneros, las sexualidades o el parentesco- implícitas en cada evaluación; por otro lado podremos intuir las consecuencias que tienen estas decisiones en la vida de las personas con una DSA y en su entorno.

Así, por ejemplo, y en lo que se refiere a la probable identidad de género futura de la persona, nos preguntamos: ¿cómo saber el género con el cual un recién nacido se identificará cuando sea adulto? Las investigaciones previas al 2006 que divagan sobre la identidad de género futura de personas con condiciones intersexuales, ofrecen recomendaciones muy generales (Money, 1975, 1976; Herdt, 1990; Martínez-Mora, 1994; Diamond y Sigmundson, 1997a, 1997b; Wilson y Reiner, 1998; Meyer-Bahlburg, 1996, 1999, 2005; Zucker, 1999, 2005; Gracia Bouthelier, 2002; Bradley, et al., 1998; Hines, 2004; Cohen-Kettenis, 2005; Mazur, 2005). No es hasta la publicación del conocido "Consenso de Chicago" cuando se estandarizan las respuestas sobre qué identidad de género se desarrollará para cada síndrome concreto (Lee et al., 2006). Aquí no se duda al recomendar reasignar el sexo femenino a personas con Síndrome de Insensibilidad a los Andrógenos Completa (CAIS), en el síndrome de Mayer-Rokitansky (MRKH), en el Síndrome de Turner, o ante una Hiperplasia Suprarrenal Congénita (HSC) con cariotipo XX y con potencial fertilidad - cuando hay estructuras internas como útero y ovarios-. Tampoco se titubea para reasignar el sexo masculino en el síndrome de Klinefelter o en casos de hipospadias. Sin embargo, la futura identidad de género sigue siendo el talón de Aquiles ante diagnósticos como el Síndrome de Insensibilidad a los Andrógenos Parcial (PAIS), la HSC o en determinadas deficiencias enzimáticas o en disgenesias (Lee et al., 2006; López Siguero, 2008).

En estos últimos diagnósticos esos terrores de género se relacionan con la potencial influencia in- controlable de los andrógenos sobre el desarrollo de género, es decir, sobre la identidad, el comportamiento y el deseo (Bradley et al., 1998; Hines et al., 2003; Meyer-Bahlburg, 2005; Zucker, 2005, Mazur, 2005; Cohen-Kettenis, 2005; Hines, 2011). Los andrógenos se presentan como responsables, tanto de los cambios de sexo como de la homosexualidad en, por ejemplo, niñas con HSC (Dessens et al., 2005; Wong et al., 2011) ${ }^{19}$. En definitiva, las estructuras o conformaciones cerebrales y neuronales serían el resultado de la acción de los andrógenos (Wilson, 2001) durante el periodo o vida fetal, con lo cual volvemos a un nuevo convencimiento esencialista sobre la localización orgánica de la identidad sexual: el cerebro y en el sistema neuronal, pero esculpidos por los andrógenos ${ }^{20}$.

Este nuevo paradigma convive en la actualidad con la incapacidad tecnológica para conocer los entresijos de la impregnación hormonal del cerebro durante el periodo embrionario y fetal. Esta limitación técnica nos descubre las contradicciones y paradojas de un modelo en el que conviven unos presupuestos teóricos fuertemente biologicistas, con una práctica clínica que respondería más a los postulados de un modelo ambientalista homófobo y tránsfobo que se consuela con la fórmula del "sexo conveniente o sexo simulacro". Así, cuando nuestros informantes médicos referían durante las entrevistas a "equivocaciones" y "errores" al reasignar a un bebé intersexual, situaban ese error en un lugar que escapa a su control y a una praxis médica correcta. Cuando un profesional decía que el resultado había sido "desastroso", querían decir: o que la identidad de género con la cual se identificó esa persona fue distinta al género que le asignaron médicamente, o que era homosexual (Gregori, 2006).

Partiendo del principio básico de que siempre se intentará conservar la fertilidad de los individuos, y de que la potencial fertilidad debería ser el elemento primordial para resolver el sexo definitivo, el último factor decisivo a la hora de asignar el sexo en casos de DSA se refiere a la capacidad funcional de los genitales externos. Esta expresión remite a la forma y al tamaño de los genitales y a su capacidad para funcionar en un tipo de prácticas sexuales centradas en el coito heterosexual. Existe un consenso sobre la forma, el tamaño y las funciones que debe tener un cuerpo para ser considerado "normal". Muy lejos de lo que la naturaleza nos presenta, en nuestro imaginario cultural existen pocas posibilidades morfológicas para hablar de genitales normales. Esta escasez se materializa a través de gráficas, escalas consensuadas y estándares biomédicos con los que se diseña el margen de 
cuerpos posibles. Una amplia variedad de términos y cifras delimita los márgenes de lo normativo y patologiza las variables que no se ajustan a este constructo. Entre ellas encontramos gráficas sobre morfologías, tamaños y disposiciones de órganos sexuales internos y externos - penes, clítoris y vaginas-; escalas para evaluar el desarrollo de mamas, de genitales externos o del vello pubiano en la pubertad - estadios de Tanner (Parera et al., 2001) - , así como clasificaciones en donde se exponen los diferentes grados de "variabilidad" - en medicina se habla de "ambigüedad" - de morfologías genitales, como son las escalas de Prader - la clasificación de Lucks para genitales ambiguos (Lucio y Ábrego, 2003). Siguiendo esta lógica, un micropene se convertirá en clítoris hipertrofiado en el instante en el cual la reasignación de sexo se incline hacia lo femenino. Tal y como sugería Laqueur (1994), estas escalas, estándares y medidas, más que demostrar empíricamente alguna esencia fundamental sobre las diferencias entre sexos y géneros, nos devuelven reflejada una imagen ya conocida: la necesidad de perpetuar las mismas concepciones de complementariedad entre sexos con un modelo de sexualidad heterosexual y coitocéntrico.

Por "capacidad funcional" en una mujer se entenderá su capacidad para embarazarse y parir, así como para reproducir una práctica sexual heterosexual convencional. Debe, por tanto, disponer de una vagina con un diámetro y longitud suficientes para albergar un pene. Por lo que respecta al clítoris, se intentará conservar en la medida de lo posible para que esa mujer sea capaz de obtener una respuesta placentera. Sin embargo, el criterio del resultado estético - "un clítoris que no se vea" - estará por delante de la posibilidad de experimentar placer a través de él. En el caso de los varones, el valor simbólico que nuestra sociedad atribuye a las cualidades y funciones del pene, se traduce en protocolos que priorizan su respuesta sexual y funcional, a saber: tener un pene con capacidad de erección y de penetración. Sin duda hablamos de una funcionalidad dirigida hacia una reproducción social y biológica, es decir, la (in)capacidad para reproducir determinadas funciones biológicas asociadas a la feminidad o a la masculinidad y que se manifiestan en menstruaciones ausentes, vaginas impenetrables o (pa)maternidades imposibles.

Una vez valorada la posible identidad de género futura, la potencial fertilidad y la capacidad funcional de los genitales externos, las posibilidades de reconstrucción quirúrgica de esos genitales sigue siendo deter- minante. Ante limitaciones tecnológicas - como en la cirugía de faloplastia-, la decisión última continúa inclinándose hacia lo femenino; ya que, en palabras de expertos, "no existen a día de hoy cirugías correctivas adecuadas para reconstruir penes mal inervados o demasiado pequeños". Únicamente en situaciones concretas, como es el caso del déficit de 5 - $\alpha$-reductasa o la deficiencia de 17- $\beta$-HSD en los cuales se espera que exista una virilización espontánea en la pubertad, se plantea una reasignación de sexo masculina (Lee et al., 2006; López Siguero, 2008).

Los cuerpos considerados "ambiguos", "deformes", "anómalos", "ofensivos", o los que potencialmente puedan desarrollarse de forma atípica, se vigilarán y se modificarán con tecnologías médicas, tratamientos farmacológicos ${ }^{21}$, tratamiento hormonal sustitutorio (THS) o con las intervenciones quirúrgicas conocidas como "cirugía genital correctora de genitales ambiguos" - clitoridoplastias, vaginoplastias o faloplastias-. Ahora bien, el sometimiento a alguno de estos tratamientos no está exento de riesgos para la salud, de infecciones, de cicatrices, de pérdidas de función, de disminución o pérdida de sensibilidad; en definitiva, de cronicidad. A pesar de ello, la lógica biomédica considera que el daño emocional producto del rechazo social a causa de una anatomía genital atípica o de una apariencia corporal sexuada poco habitual, es mucho mayor que el posible daño físico derivado de efectos iatrogénicos de la cirugía plástica y superior a los efectos secundarios de tratamientos farmacológicos. Es por ello que la DSA se sigue considerando una "urgencia" y un peligro para el desarrollo psicológico de la persona:

“El nacimiento de un niño con ambigüedad sexual constituye un problema muy serio y una urgencia, no solo médica sino sociofamiliar, por la angustia que genera en los padres del recién nacido y por los problemas judiciales que se derivarían en caso de un error diagnóstico, con el consiguiente cambio de sexo a nivel administrativo-judicial (...). Es preciso no escatimar esfuerzos a la hora de realizar de forma rápida un diagnóstico exacto, decidir una asignación correcta de sexo y planificar los tratamientos médicos y quirúrgicos necesarios para conseguir un individuo sano, con unos genitales anatómica y funcionalmente correctos que le permitan vivir una vida adulta identificado física y psíquicamente con el sexo asignado." (Piró Biosca, 2002).

Como Kessler declarara (1998), la intervención médica está justificada a favor de producir individuos socialmente ajustados, donde "un problema social se 'cura' médicamente". 


\section{Asegurando la generización a través de la experiencia corporal}

En realidad, el aspecto por el cual se ha popularizado la "intersexualidad" ha sido por el de unos genitales atípicos en recién nacidos y por las cirugías que se les practica para "normalizarlos". De hecho, cuando escuchamos la palabra "intersexualidad", inmediatamente pensamos en bebés de los cuales no se ha podido decir si es niño o niña al nacer. Pero lo cierto es que eso que hemos ido conociendo como "intersexualidad"22 no siempre se diagnostica al nacimiento, y en ocasiones se detecta más tarde, en la adolescencia o en la edad adulta. Para aquellas personas con una DSA que nunca entraron en circuitos institucionales médicos, su DSA nunca se convertirá en etiqueta diagnóstica.

Las causas por las cuales llegan a diagnosticarse estas situaciones son diversas: unos genitales inusuales que no se habían descubierto anteriormente, una hernia inguinal en una niña, una pubertad retrasada o incompleta, la virilización en una mujer - como el crecimiento de barba-, una amenorrea primaria ausencia de la primera menstruación-, el desarrollo de pechos en chicos o la hematuria cíclica y ocasional en un niño - sangrado abundante mensualmente- (Sánchez-Planell, en Martínez-Mora, 1994; Lee, 2006). A excepción de la hernia en la niñez, este listado de descubrimientos médicos se traduce en la ausencia de determinados signos de desarrollo masculino o femenino en el sentido esperado, o en la aparición de rasgos físicos que se asocian al sexo contrario. Son esos marcadores de género que aparecen durante la explosión hormonal de la adolescencia, momento en el cual los caracteres sexuales secundarios dibujan nuevos paisajes corporales. Dentro de este registro cabría añadir la esterilidad, un motivo de consulta muy habitual en hombres que terminan siendo diagnosticados con un síndrome de Klinefelter, o en mujeres que acaban con una etiqueta de CAIS o de Síndrome de Rokitansky.

En estos casos, la cirugía será la mediadora en ese "proceso de generización" al que hacía referencia Mauro Cabral (2005): un "simulacro" de reproducción biológica según el cual, a pesar de que determinadas personas, por ejemplo, nunca podrán ser fértiles (por no poseer las estructuras internas necesarias para esa función), igualmente se les construirá una vagina. Una neovagina que posibilitará un coito heterosexual -en el que un pene penetra una vagina - como una práctica que permite el acceso a la heteronormatividad en una teatralización de la fusión y complementariedad entre los sexos. Según esto, la posibilidad de "encar- nar" una práctica sexual reproductiva, bastaría para garantizar la pertenencia a uno u otro sexo.

Pero como ya advertimos, la cirugía tiene límites. Las hormonas sintéticas o determinados tratamientos farmacológicos acaban siendo el complemento perfecto y necesario a una "cirugía correctiva", porque como apuntaba Moisés Martínez (2005) para casos de transexualidad, "ellas son las verdaderas responsables de la transformación física". Los efectos de la química hormonal se sobrevaloran en tal medida, que no solo tienen la capacidad de "crear" mujeres u hombres, sino que además se considera que esas mujeres y esos hombres pueden representar ideales de feminidad o masculinidad. Tal y como afirmaba un profesional médico respecto al resultado del tratamiento con estrógenos de una paciente a la que se le habían extirpado sus gónadas testículos, "es guapa, rubia y de pelo largo". Por otro lado también se espera de ellas que eviten las "sorpresas inesperadas" de los cuerpos en crecimiento. Con esta expresión los profesionales médicos remiten a lo que en una ocasión un endocrinólogo llamaría "la madre del cordero cuando llega la pubertad"; esto es, que después de haber asignado un sexo a un recién nacido, al llegar a la pubertad las gónadas pueden entrar en funcionamiento y dirigir el desarrollo físico hacía el sexo contrario al esperado.

Nos atreveríamos a afirmar que las hormonas, o lo que se espera de ellas, son en parte las responsables de la creencia en la identidad de género. El cuerpo vivido, esculpido a golpe de hormonas, huele diferente, cambia el tono de voz, hace crecer pelo en la cara o los pechos cuando se toma testosterona o estrógenos sintéticos. Probablemente ese mismo cuerpo también experimente cambios de humor, mayor o menor energía o fuerza física, más o menos libido, etc. Esos cambios corporales unidos al efecto simbólico que otorgamos a las hormonas sexuales -especialmente a la testosterona-, seguramente cambien nuestras relaciones cotidianas; tal vez nos transporten en poco tiempo a un cuerpo nuevo, a una nueva identidad. La hormonoterapia o la administración de hormonas en dosis cada vez más altas, acaba siendo el mejor seguro de vida para una identidad verdadera, única y estable.

\section{VISIBILIZACIÓN Y POLITIZACIÓN DE IDENTIDADES TRANSGRESORAS: ACTIVISMOS Y MICRORESISTENCIAS}

En la actualidad, los protocolos de atención a las personas con una DSA están siendo revisados minuciosamente. Este escrutinio no es arbitrario, sino más bien la consecuencia de todo un movimiento político 
de visibilización de la intersexualidad que comenzó en los años 90, principalmente en el contexto norteamericano. Volviendo de nuevo atrás sobre las memorias de Alexina Barbin, comprobamos que la crueldad y el dolor descritos por la autora no fueron el resultado de un supuesto error de asignación al nacimiento, sino el producto de las experiencias y las decisiones que se derivaron de sus encuentros médicos. Barbin recordaba así su encuentro con el doctor T., al que visitó por primera vez por los fuertes dolores que experimentaba en su ingle izquierda:

"Las respuestas que di a sus preguntas resultaban para él un enigma en lugar de aportar algún rayo de luz. Quiso sondarme. Sabemos que de cara a un enfermo un médico goza de ciertos privilegios que nadie osaría discutir. Durante esta operación, le oía suspirar como si no estuviera satisfecho de su examen (...) De pie, junto a mi cama, el doctor observaba con una atención cargada de interés. Se le escapaban sordas exclamaciones del tipo: ‘iDios mío, será posible!'.” (Barbin, Foucault y Serrano, 1985).

Veremos cómo este fragmento de mitad de siglo XIX con las memorias de Barbin no está tan alejado de los primeros testimonios que, principalmente a través de Internet, visibilizaron y denunciaron un siglo después las conocidas como "prácticas de normalización" sobre las personas con una DSA. Nos atreveríamos a decir que estas memorias constituyen el texto fundacional de lo que se ha conocido como "movimiento político intersex"23. El hecho excepcional de que Barbin relatara su vida y sus reflexiones en primera persona constituye un antes y un después en las narrativas de la "intersexualidad". Sus palabras sellan la entrada en un nuevo paradigma en el cual los sujetos "expertos" pasan a ser esos "otros pacientes", hasta el momento pasivos y asustados. Algunas de estas voces reivindican públicamente su existencia "intersexual" o "hermafrodita" y denuncian los procesos médicos, sociales y tecnológicos a los que fueron sometidos para hacer encajar su cuerpo en un modelo binario. Autores como Martha Coventry (1999), Howard Devore (1999), Kim (1999), Ángela Moreno (1999), Mauro Cabral (2003), Cheryl Chase (2005), Curtis E. Hinkle (2006), Sarah Graham (2006) - se podría añadir un largo etcétera- daban a conocer el estigma y el tabú que soportaron. Sus reflexiones íntimas cuestionan las prácticas médico-tecnológicas sin consentimiento de los afectados, y problematizan la conocida como "matriz heterosexual" de Butler (2001) o el marco normativo que relaciona el sexo, el género y la sexualidad, estableciendo una cadena causal entre ellos ${ }^{24}$ :
“Nací con genitales ambiguos. Un doctor especializado en intersexualidad deliberó durante tres días - sedando a mi madre cada vez que preguntaba qué problema había con su bebé- antes de concluir que yo era un varón con micropene, completa hipospadias, los testículos sin descender, y una extraña apertura extra detrás de la uretra. Se cumplimentó para mí un certificado de nacimiento de varón y mis padres comenzaron a educarme como un chico. Cuando tuve un año y medio mis padres consultaron con un equipo diferente de expertos [...] Juzgaron mi apéndice genital como inadecuado como pene, demasiado corto para marcar efectivamente estatus masculino o para penetrar a mujeres. Como mujer, sin embargo, sería penetrable y potencialmente fértil." (Chase, 2005, 91).

Mientras hablo, yo sé que para mi cirujano formo parte de su pasado, de un pasado nebuloso de pacientes que van y vienen. Mientras yo viva él no podrá formar parte del mío: llevo las marcas de sus ideas sobre el género y la sexualidad grabadas en el cuerpo para siempre. Convivo con ellas todos los días, forman parte del paisaje cotidiano de mi piel, están ahí para ser explicadas cada vez que me desnudo, responden con el silencio de la insensibilidad que su práctica instaló en mi experiencia íntima de lo corporal." (Cabral, 2003, 124).

En este contexto han ido surgiendo algunas organizaciones activistas intersex o de defensa de los derechos de las personas con una DSA, entre las que destacan la Intersex Society of North America (ISNA) ${ }^{25}$ de 1993 o la Organisation Internationale des Intersexués $(\mathrm{OII})^{26}$ de 2003, cada una con objetivos y agendas bastante divergentes y en ocasiones enfrentadas. La principal crítica aportada por la ISNA recae sobre las "cirugías de normalización de genitales ambiguos", argumentándose que con las mismas se dañan la función sexual (por retirar tejido conectivo con capacidad sensitiva) disminuyendo la respuesta erotosexual. A esta objeción añaden que los resultados de la reconstrucción cosmética no son casi nunca satisfactorios, reclamando para sí el derecho a la autodeterminación para decidir por ellas mismas si en algún momento desean o no, pasar por una intervención quirúrgica de sus genitales (Nieto, 2003, 81).

Una de las aportaciones más insólitas de estos colectivos fue la elaboración de categorías propias que, en ocasiones parodiando la terminología médica, criticaban un modelo de atención médica en la DSA patologizador y paternalista (Carter, 1998; Chrysalis, 1998). En este trabajo de contestación, uno de los mayores esfuerzos se volcó en la disolución de términos como "patológico", "síndrome", "malformación", "errores" o "quimeras", y su sustitución por expresio- 
nes tales como "variaciones de la mujer y el hombre estándar" (Dreger, 1998b). En la misma línea, Suzanne Kessler (1998) hacía una crítica a las rebautizadas como "intervenciones quirúrgicas de normalización de genitales":

"lo que la medicina llama 'avances en corrección quirúrgica' es denominado por las personas intersexuales 'mutilación genital'. Es más, lo que para la profesión médica, antes de la intervención quirúrgica, es un genital 'deformado', para un intersexual es un genital 'intacto'; lo que para la medicina, en el momento de la intervención, es 'crear', para los intersexuales es 'destruir'; $y$, finalmente, lo que para los cirujanos, después de la intervención, es un genital 'corregido'/'normal', para los intersexuales es un genital 'dañado'/'artificial'." (Kessler, 1998; citada en Nieto, 2003).

Aunque estas críticas se apoyaron de todo tipo de estudios y disciplinas, parte de las justificaciones se nutrieron de trabajos antropológicos o etnografías que ofrecen ejemplos de variabilidad cultural en relación a los sexos/géneros/sexualidades. En ellos descubrimos diferentes reacciones a la DSA, así como sociedades que reconocen la existencia de personas con un "tercer sexo" y en las que se crean las correspondientes estructuras, funciones y roles de género para ubicarlas ${ }^{27}$. Otros trabajos que compararon las cirugías de normalización de genitales occidentales con las prácticas conocidas como rituales de mutilación genital femenina (MGF) que se realizan en determinadas culturas, argumentaron que los discursos anti-MGF que desde occidente critican estos rituales, parten de presupuestos etnocéntricos. Para Wairimu Ngaruiya Njambi (2004), estos discursos olvidan las prácticas y tecnologías que se aplican sobre los cuerpos considerados ambiguos en Occidente, simplemente porque parten de la consideración de ser "médicamente necesarios".

La proliferación de estos trabajos y testimonios no dejaron indiferente a la comunidad médica, de manera que en el año 2006 aparecía el Consensus statement on management of intersex disorders (Lee et al., 2006), un consenso médico internacional para gestionar la DSA, elaborado entre profesionales médicos y algunas personas "afectadas" 28 y familiares de estas. Este documento, el "Consenso de Chicago", inauguraba toda una serie de controversias, conflictos y alianzas que perduran entre la comunidad médica, pacientes y familiares desde dentro y fuera de grupos de apoyo (GA) de condiciones concretas y entre los movimientos políticos internacionales por los derechos sexuales y humanos de personas intersexuales, transexuales o transgénero.
Una de las primeras controversias resultantes de este consenso giró en torno al efecto performativo de las categorías médicas. El consenso sustituía el término "intersexualidad" o "hermafroditismo" por el acrónimo "DSD/ADS". Para unos, esta sustitución permitiría crear alianzas con la comunidad médica a fin de evitar o retrasar intervenciones quirúrgicas y tratamientos innecesarios. Además conseguiría desestigmatizar y desidentificar a muchas de las personas que no se identifican con esa recién estrenada identidad intersex. Para otros, los términos "anomalía", "alteración" o "disorder", suponían una vuelta atrás en el logro identitario que entrañaba el término "intersex", además de eliminar su potencial para un cambio en el sistema fuerte de sexo/género (Morris, 2006; Simmonds, 2006; Gregori, Gallego, García-Dauder, 2007; Dauder y Romero, 2012).

Es cierto que, en gran medida, la subjetividad de las personas etiquetadas en posiciones fronterizas respecto al sexo/género está atravesada por la interpelación que supone el diagnóstico, y tal y como relata Bernice Hausman (1998), la transexualidad, al igual que la intersexualidad es una subjetividad literalmente creada o posibilitada por las tecnologías médicas y los constructos que estas mantienen acerca del género y del sexo. Sin embargo, en este juego de apropiaciones identitarias, de resignificaciones y reinterpretaciones, se abren importantes debates sobre las exclusiones que se generan con el uso de unas $u$ otras categorías sociales. Coincidimos con Dauder y Romero (2012) cuando afirman que cualquier acto de nombrar se puede considerar un ejercicio político con efectos psicosociales. Cada término o categoría nosológica arrastra una carga ideológica y moral que (re)produce realidades bajo un efecto performativo. Mientras unos términos hablan de fluidez en los cuerpos y los sexos, otros refuerzan el dimorfismo sexual y las convenciones de sexo/género/sexualidad. Para unos, las luchas son personales y privadas; para otros, sociales y políticas. Unos reclaman derechos humanos y sexuales; otros, soluciones médicas.

En unos y en otros casos, e independientemente de que los conocimientos surjan desde acciones más politizadas por parte de grupos activistas intersex o desde la experiencia cotidiana y acciones colectivas de $\mathrm{GA}^{29}$, siempre se hace un uso estratégico de las categorías en base a intereses particulares y a una ideología o moral. Así, por ejemplo, acudir a una consulta médica rutinaria - por un simple resfriado o para una revisión- desvelando una ADS, puede suponer interminables horas de espera, pruebas analíticas y radiológi- 
cas innecesarias, así como exponerse a los diferentes desfiles - parades- de especialistas ${ }^{30}$. En situaciones como estas, algunas personas afectadas aprovechan su conocimiento de las instituciones médicas y del discurso biomédico y eligen estratégicamente términos más generales e inespecíficos como el de "hipogonadismo"31 - falta de función en los genitales-, para ahorrarse tiempo e inconvenientes.

Otro ejemplo de ello es el rechazo que han expresado algunas asociaciones al término "transexualidad" optando por el de "síndrome de Harry Benjamin" (SHB), que definen como una condición intersexual en la cual la diferenciación sexual a nivel neurológico y anatómico no se corresponden ${ }^{32}$. Entre sus argumentaciones critican la asociación que se hace de esta "condición intersexual" con corporalidades y movimientos transgénero y que, en su opinión, guardan relación con movimientos sociales radicales (movimientos LGTB o queer), con situaciones de marginalidad (prostitución) y con identidades y cuerpos ambiguos o poco definidos. Por otra parte, en el contexto sanitario español, la posibilidad de ser reconocidos como intersexuales podría suponer estratégicamente muchas ventajas. Por un lado, se evitarían los costosos e injustos exámenes psiquiátricos que en nuestro país se realizan a personas transexuales. Por otro, si lo cubriera la sanidad pública, tendrían acceso gratuito y rápido a intervenciones quirúrgicas, si fueran deseadas.

En cualquier caso, la redefinición y la contestación a los discursos y categorías médicas por parte de las personas interpeladas ha supuesto una reapropiación del conocimiento "experto" en un firme gesto de autodeterminación. Entrábamos de lleno en el periodo que Alice Dreger (1999) bautizó como The Age of Consent - La Era del Consentimiento-, y que estrenaba una serie de exigencias por parte de "afectados", "pacientes" o "activistas". Estos exigirían que se les diera toda la información sobre su condición -completa y en positivo-, que no se les expusiera a los desfiles médicos y que se utilizaran una terminología y unas imágenes no patologizadoras - especialmente la de niños desnudos sobre cuadrículas y bandas negras sobre los ojos y las de intervenciones de genitales-. Igualmente, solicitarían una moratoria de las intervenciones quirúrgicas con fines estéticos, al menos hasta que los afectados pudieran dar el consentimiento informado o hasta que los profesionales médicos completaran exhaustivos estudios retrospectivos en los que se probara que los resultados de intervenciones pasadas habían sido positivos (Kipnis y Diamond, 1999). Por último, se reclamaría la realización de estu- dios a largo plazo sobre satisfacción y calidad de vida en pacientes (Preves, 2003).

La suma de todas esas quejas y luchas condujo a una "crisis del paradigma de atención médica" (TamarMattis, 2008), de manera que muchos profesionales reconocieron que un nuevo paradigma de tratamiento de la intersexualidad se estaba empezando a imponer. Concretamente Bruce Wilson y William Reiner (1998) aseguraron que el viejo modelo de tratamiento tecno-céntrico estaba empezando a sustituirse por uno nuevo, éticamente informado y centrado en el paciente. El viejo paradigma era insostenible ya que contradecía uno de los axiomas médicos: "Ante todo, no dañar" (Primum, non nocere) (Kipnis y Diamond, 1999; Ford y K-K, 2001). Entre las principales premisas de este nuevo modelo se incluía la de ofrecer información completa y honesta tanto a padres como a pacientes, fomentar el encuentro y el apoyo entre iguales - derivando a GA-, proporcionar apoyo profesional y limitar las cirugías tempranas en la medida de lo posible (Diamond y Sigmunson, 1997).

\section{DIATRIBAS EN LA “ERA DEL CONSENTIMIENTO”}

Los conceptos de ética e intersexualidad comienzan a aparecer de manera inseparables (Dreger, 1999; Kipnis y Diamond, 1999; Sytsma, 2006; Consortium of the management of DSD, 2006; Halifax Resolution, 2009; Wiesemann et al., 2009; Karkazis y Rossi, 2010; Hutson, Warne y Grover, 2012, etc.). Las evidencias de cambio también se reflejan en el aumento del número y variedad de publicaciones que abordan cuestiones como el consentimiento informado, la composición de los equipos multidisciplinares, la necesidad de resultados de investigaciones a largo plazo, los derechos de los padres a la hora de tomar decisiones sobre las cirugías en sus hijos. Cuestionan también si se debe intervenir quirúrgicamente a los niños para que encajen en las normas de la sociedad que conciben el género solo en términos binarios estereotípicos. Las respuestas a todas estas cuestiones no son simples porque comprometen la estructura y el funcionamiento de los respectivos sistemas sanitarios, jurídicos y educativos; además de nuestras propias construcciones sociales y culturales de cuerpo, género, parentesco o familia. Pero el futuro va a seguir haciéndonos preguntas cada vez más complejas. Con el perfeccionamiento de las tecnologías de diagnóstico y tratamiento para producir cuerpos "estándar", sin complicaciones ni infecciones, o con la investigación exhaustiva en diagnóstico genético preimplantacional (DGP) se plantean nuevos interrogantes: ¿quién tiene el derecho de decidir sobre 
nuestro propio cuerpo? Si contamos con la baza tecnológica para reconstruir perfectamente un ideal utópico de naturaleza humana, ¿quién necesita cambiar lo social y lo cultural —creencias, mitos, prejuicios-?

La multipremiada película XXY (2007) de Lucía Puenzo fue uno de los primeros largometrajes de ficción que planteó al gran público la complejidad y las contradicciones implícitas en las condiciones de existencia de una persona intersexual. Su protagonista, Alex, una adolescente de quince años con una DSA, resolvía con sencillez lo que hasta el momento no han conseguido sofisticadas clasificaciones y explicaciones sobre la naturaleza del sexo, del género y de la sexua- lidad. En la película se nos hace saber que, al nacimiento de Alex, sus padres decidieron no someterla a ninguna intervención quirúrgica, esperando que más adelante ella pudiera decidir por sí misma. Llegada la pubertad, Alex se muestra reacia a seguir tratamientos hormonales de por vida mientras sus padres $-\mathrm{y}$ también el espectador - esperan el momento de "su elección", es decir, el momento en el cual se decante por una identidad de género como mujer o como varón y desvele el pulso de su deseo. La inesperada respuesta de Alex resulta desconcertante: "¿Y si no hay nada que elegir?".

\section{NOTAS}

1 Las pruebas de género a las que someten a atletas "sospechosas de ambigüedad" en deportes de élite fueron prohibidos por el Comité Olímpico Internacional (COI) en 1999. Sin embargo, estos se han seguido realizando a personas "sospechosas de ser hombres que compiten en pruebas de mujeres", tal y como sucedió en los Juegos Olímpicos de Pekín (2008) o en los Mundiales de Atletismo de Berlín (2009).

2 El diario australiano The Daily Telegraph desveló el 11 de septiembre de 2009 los resultados del "test de género" que se le practicó a Semenya e hizo saltar la noticia a nivel internacional (Hurst, 2009).

3 Después de un largo periodo ocupando titulares de prensa (Garrido, 2009; Hart, 2009; Marca, 2009; San Román, 2009), en noviembre de 2009 se le permitió a la atleta conservar su medalla y el dinero del premio. Tras la evaluación de un grupo internacional de expertos médicos, en julio de 2010 se la volvió a dejar competir como mujer (Ginnane, 2011).

4 La atleta india Santhi Soundarajan fue desposeída de su medalla de plata en los Juegos Asiáticos porque, según el Comité Organizador, el test que se le realizó, presentaba un número de cromosomas " $Y$ " más elevado del permitido (El País, 2006; El Mundo, 2006).

5 En los Juegos Olímpicos de Seúl de 1985, María José Martínez Patiño, campeona de España de los 60 y 100 metros vallas, fue suspendida por no superar un control de género al detectársele una "alteración de origen genético", es decir, por poseer en su fórmula cromosómica una XY (Fausto-Sterling, 2006; Nieto, 2003).

6 Término acuñado por Charles Henri Marc (1771-1840) en Vázquez y Cleminson $(2011,130)$.

7 Vázquez y Cleminson $(2011,125)$ utilizan la cita de Huertas $(1929,9)$, quien escribió: "Marañón es nuestro Darwin. Un Darwin muy siglo XX".

8 Klebs (1876) dividió el hermafroditismo en dos clases principales basándose en las gónadas, verdaderos y falsos, que luego subdividió en varios tipos: (I) hermafrodita verdadero (presencia de ovarios y testículos en el mismo individuo): (a) bilateral: un testículo y un ovario en cada lado del cuerpo; (b) unilateral: en un lado un ovario o un testículo, y en el otro lado un ovario y un testículo; (c) lateral (hermafroditismo alternado): un ovario en un lado y un testículo en el otro. (II) Pseudohermafroditismo (hermafroditismo espurio: doble aparato genital externo con un solo tipo de glándula sexual): (a) masculino: presencia de testículos y desarrollo evidente de genitales femeninos; (b) femenino: presencia de ovarios con predominancia de genitales masculinos (Dreger, 1998a).

9 El análisis de Dreger (1998a) refiere a lo sucedido en Francia e Inglaterra a finales del siglo XIX

10 Utilizo ahora y utilizaré en adelante e término "reasignación" en lugar de la utilización médica del término "asignación" de sexo, siguiendo la propuesta de Gallego (2006), "se reasigna al recién nacido porque en realidad ya hubo una asignación previa, solo que ambigua o indefinida".

11 Refiriéndose a una supuesta masculinización de la mujer durante el embarazo.

12 Definida por Marañón como aquellas relaciones sexuales mantenidas entre hombres únicamente en momentos de aislamiento continuo, guerra, y debido a que su particular naturaleza les impide reprimir el impulso sexual.

13 Una supuesta feminidad o afeminamiento asociado al principio de la adolescencia en hombres.

14 En este caso alude a una esperada masculinización en la mujer al aparecer la menopausia y al alcanzar la vejez (cambios en las formas corporales, crecimiento de vellos en cara, etc.).

15 El modelo unisexo proviene de las ideas galénicas sobre la procedencia de la mujer a partir del varón, con un aparato reproductor esencialmente idéntico al del hombre, pero "al revés", una "introversión del cuerpo masculino" (Laqueur, 1994).

16 Según la "teoría biosocial de la interacción" del autor, es la naturaleza la que pone límites a la identidad sexual y a la preferencia de pareja, y es dentro de estos límites donde las fuerzas sociales interactúan y donde se formula el rol de género.

17 El trabajo de campo en curso al que referimos analiza las discusiones e in- 
tercambios que se están produciendo actualmente dentro de la triada DA-ASGA (Dispositivos Asistenciales-Actores Sociales-Grupos de Apoyo) y en el contexto español (Gregori, 2006, en prensa).

18 Es necesario precisar que en este artículo presentamos exclusivamente líneas generales, sin detenernos en las especificidades de cada forma de DSA. En un análisis pormenorizado descubriríamos la complejidad que envuelve cada decisión y los dilemas que se les plantean a todos los actores implicados.

19 Las referencias bibliográficas citadas simplemente apoyan el discurso repetido por los expertos médicos españoles en congresos médicos específicos - por ejemplo, de Endocrinología Pediátricao en los encuentros anuales de Grupos de Apoyo de condiciones específicas.

20 En esta lógica médica sobre la identidad de género de los protocolos contemporáneos de atención en personas con DSA nos reencontramos con el desencuentro Money-Diamond.

21 Nos referimos en concreto a los tratamientos con glucocorticoides o dexametasona que se utilizan para evitar la "virilización" en personas XX con HSC. En la actualidad hay abierta una fuerte polémica sobre el uso y experimentación con esta molécula en mujeres embarazadas con riesgo de tener niñas con HSC, ya que además de no curar la HSC y de provocar riesgos mayores para la salud, la única indicación persigue evitar el lesbianismo y el supuesto comportamiento masculino de estas chicas (Dreger, Feder y Tamar-Mattis, 2012).
22 Más adelante introduciremos el debate actual sobre las formas de nombrar la DSA.

23 Utilizamos la forma inglesa para hacer notar el contexto anglosajón en el cual surge este movimiento político.

24 Butler puntualiza cómo el sexo es el núcleo natural que se actualiza en las prácticas de género, entre las que se incluye un deseo y una práctica sexual orientados hacia un objeto del sexo "opuesto" (Butler, 2001).

25 La ISNA fue fundada en 1993 por la activista norteamericana Cheryl Chase y cierra sus puertas en marzo de 2008, trasladando sus propuestas y objetivos a la organización Accord Alliance.

26 La Oll fue fundada en 2003 por el activista intersex Curtis Hinkle y en la actualidad se ha constituido como el principal grupo de presión a nivel internacional que lucha a favor de los derechos humanos para las personas intersexuales.

27 Al respecto destacan los trabajos de Gilbert Herdt (1988) sobre los guevedoce de la República Dominicana; los de Edgerton (1964) sobre los serer de Kenya; los de Will Roscoe (2003) sobre los berdache de las tribus norteamericanas; 0 los de Serena Nanda (1990) sobre los hijra de la India.

28 "Afectadas" es la forma más utilizada para referirse a sí mismas de aquellas personas diagnosticadas por una condición intersexual o por una ADS, pero solo cuando aluden a experiencias colectivas dentro de GA, o a problemáticas compartidas en sus itinerarios asistenciales, etc.

29 Distinguimos entre GA y colectivos de activismo intersex, para señalar el diferente contexto de procedencia. No podemos hablar de activismo político intersexual en España; sin embargo, sí que descubrimos unos cuantos GA, cada uno de ellos en relación con un síndrome o condición intersexual/ADS. Estos grupos funcionan como actores colectivos, donde la información es el bien más preciado que se hace circular en una red de reciprocidades. Son espacios o contextos que favorecen el proceso de reflexión y de crítica, de forma que el empoderamiento individual se convierte en contestación colectiva o viceversa (Canals, 2002).

30 Sharon Preves (1998) utilizó el término "parades" para referirse a los desfiles de médicos observando, fotografiando y tocando los genitales considerados ambiguos de las personas intersexuales en sus visitas constantes a médicos y hospitales.

31 Algunas de las causas de hipogonadismo se asocian con tumores, traumatismos, fármacos, radioterapia o cirugías (Martul, 2000), con lo cual ya no se señala específicamente una DSA.

32 Al respecto se puede encontrar información en el sitio web del Síndrome de Harry Benjamin: http://www.shb-info. org/

\section{BIBLIOGRAFÍA}

Álvarez de Gregori, C. (2001). Sobre la mutilación genital femenina y otros demonios. Barcelona: Universidad Autónoma de Barcelona.

Barbin, H.; Foucault, M.; Serrano, A. (1985). Herculine Barbin, Ilamada Alexina $B$. Madrid: Editorial Revolución.

Butler, J. (2001). El género en disputa. El feminismo y la subversión de la identidad. Barcelona: Paidós.

Butler, J. (2002). Cuerpos que importan. Sobre los límites materiales y discursivos del "sexo". Buenos Aires: Paidós.
Bradley S. J.; Oliver G. D.; Chernick A. B.; Zucker K. J. (1998). "Experiment of nurture: ablatio penis at 2 months, sex reassignment at 7 months, and a psychosexual follow-up in young adulthood". Pediatrics, vol. 102, no1, pp. 1-5.

Cabral, M. (2003). Pensar la intersexualidad, hoy. En D. Mafia (Comp.), Sexualidades migrantes. Género y transgénero (pp. 117-127). Buenos Aires: Seminaria.

Cabral, Mauro (2005). "Cuando digo intersex: un diálogo introductorio a la intersexualidad". Cadernos Pagu, núm 24, pp. 283-284.
Cabral, M. (2009). Interdicciones. Escrituras de la intersexualidad en castellano. Córdoba: Anarrés Ed.

Canals, J. (2002). El regreso de la reciprocidad. Grupos de ayuda mutua y asociaciones de personas afectadas en la crisis del Estado de Bienestar. (Tesis inédita de maestría o doctorado). Tarragona: Universitat Rovira i Virgili.

Carter, R. (1998). "The Murk Manual: How to Understand Medical Writing on Intersex". Chrysalis: The Journal of Transgressive Gender Identities, vol.2, no 5, pp. 10 y 30 
Chase, C. (2005). "Hermafroditas con actitud: Cartografiando la emergencia del activismo político intersexual". En GTQ (Grupo de Trabajo Queer), El eje del mal es heterosexual. Figuraciones, prácticas y movimientos feministas queer (pp. 87-108). Madrid: Traficantes de Sueños.

Cleminson, R.; Medina, R. M. (2004). “¿Mujer u hombre? Hermafroditismo, tecnologías médicas e identificación del sexo en España, 1860-1925". Dynamis, vol. 24. Universidad de Granada.

Cohen-Kettenis, P. T. (2005). “Gender Change in $46, \mathrm{XY}$ Persons with $5 \alpha$-Reductase- 2 Deficiency and $17 \beta$-Hydroxysteroid Dehydrogenase-3 Deficiency". Archives of Sexual Behavior, vol. 34, no 4, pp. 399410. DOI: 10.1007/s10508-005-4339-4

Colapinto, J. (2001). As nature made him. The boy who was raised as a girl. New York: Harper Collins.

Consortium on the Management of Disorders of Sex Development (2006). Clinical guidelines for the management of disorders of sex development in childhood. Recuperado de http://www.accordalliance.org/dsd-guidelines.html

Coventry (1999). "Finding the Words". En A. D. Dreger (Ed.), Intersex in the age of ethics (pp.71-8). Maryland: University Publishing Group.

De Gabriel, N. (2010). Elisa y Marcela. España: Libros del Silencio.

De Lauretis, T. (1989). Technologies of gender: Essays on theory, film, and fiction. London: MacMillan.

Denny, D.; Chase, C.; Coventry, M. (Eds.). (1997-1998). "Intersex Awakening". Chrysalis: The Journal of Transgressive Gender Identities, vol. 32, no5.

Dessens, A. B.; Slijper, F. M.; Drop, S. L. (2005). " Gender Dysphoria and Gender Change in Chromosomal Females with Congenital Adrenal Hyperplasia". Archives of Sexual Behavior, vol. 34, n응 4, pp. 389-397. DOI: 10.1007/s10508005-4338-5

Devore, H. (1999). "Growing up in the surgical maelstrom". En A. D. Dreger (Ed.), Intersex in the age of ethics (pp. 79-82). Maryland: University Publishing Group.

Diamond, M. (1965). “A Critical Evaluation of the Ontogeny of Human Sexual Behavior". The Quarterly Review of Biology, vol. 40, no 2, pp. 147-175.

Diamond, M. (1968). "Genetic-Endocrine Interactions and Human Psychosexuality". En M. Diamond (Ed.), Perspectives in Reproduction and Sexual Behavior. (pp. 417-443). Indiana: Indiana University Press.

Diamond, M.; Sigmundson, K. (1997a). "Management of intersexuality. Guidelines for dealing with persons with ambiguous genitalia". Archives of Pediatrics and Adolescent Medicine, vol. 151, $\mathrm{n}$ 응 10, pp. 1046-1050.

Diamond, M.; Sigmundson, K. (1997b). "Sex Reassignment at Birth: A Long Term Review and Clinical Implications". Archives of Pediatrics and Adolescent Medicine, vol. $151, \mathrm{n}$ ㅇ 10, pp. 298-304.

Dreger, A. D. (1998a). "A History of Intersexuality: From the Age of Gonads to the Age of Consent". En A. D. Dreger (Ed.), Intersex in the Age of Ethics. (pp. 5-23). Hagerstown: University Publishing Group.

Dreger, A. D. (1998b). Shifting the Paradigm of Intersex Treatment. Recuperado de http://www.isna.org/compare

Dreger, A. (1999). Intersex in the Age of Ethics. Maryland: University Publising Group.

Dreger, A.; Feder, E. K.; Tamar-Mattis, A. (2012). "Prenatal Dexamethasone for Congenital Adrenal Hyperplasia. An Ethics Canary in the Modern Medical Mine". Bioethical Inquiry, vol. 9, pp. 277294. DOI 10.1007/s11673-012-9384-9

El Mundo (2006). La subcampeona de 800 metros es él. Recuperado de http://www.elmundo.es/elmundodeporte/2006/12/19/masdeporte/1166525963.html

El País (2006). Una atleta india pierde su medalla en los Juegos Asiáticos por las dudas sobre su sexo. Recuperado de http://deportes.elpais. com/deportes/2006/12/19/actualidad/1166516515_850215.html

Fausto-Sterling, A. (2006). Cuerpos sexuados. Barcelona: Melusina.

Ford, K-K (2001). "'First, do no harm' - the fiction of legal parental consent to genital-normalizing surgery on intersexed infants". Yale Law Policy Rev., vol. 19, pp. 469-488.

Foucault, M. (1985). Herculine Barbin Ilamada Alexina B. Madrid: Revolución.

Gallego, C. (2006). La construcción tecnosocial del sexo. (Trabajo de Investigación para Diploma de Estudios Avanzados). Universidad Complutense de Madrid.

García Dauder, S.; Romero, C. (2012). “Los desplazamientos políticos de las categorías médicas: Actores, discursos y relaciones en la controversia 'Disorders of sex development' versus 'Intersex". En E. Pérez Sedeño; R. Ibañez (Coord.), Cuerpos y diferencias. (pp. 231-240). Madrid: Ed. Plaza y Valdés.

Garrido, C. (2009). ¿Padece Semenya el Síndrome de Insensibilidad Androgénica?. Recuperado de http://www.abc. es/20090918/sociedad-salud/semenya-200909161748.html

Ginnane, Maxx (2011). Too fast to be a woman?: The story of Caster Semenya. UK: BBC

Gracia Bouthelier, R. (2002). “Anomalías de la diferenciación genital". En Sociedad Española de Endocrinología Pediátrica (Ed.), Estados intersexuales e hipogonadismo. (pp. 83-93). Barcelona: J\&C Ediciones Médicas.

Graham, S. (2006). The secret of my sex. Recuperado de http://www.independent.co.uk/life-style/health-and-families/health-news/the-secret-of-mysex-411032.html

Gregori, N. (2006). "Los cuerpos ficticios de la biomedicina. El proceso de construcción del género en los protocolos médicos de asignación de sexo en bebés intersexuales". AIBR, vol. 1, no. 1. Recuperado de www.aibr.org/antropologia/01v01/ articulos/010106.pdf

Gregori, N. (2008). "Sexos y deseos inapropiados". En A. Téllez y J. E. Martínez (Coords.), Sexualidad, género, cambios de roles y nuevos modelos de familia. (pp. 169-203). Elche: Ed. S.I.E.G.

Gregori, N. (en prensa). “'Llegar a ser' mujer/hombre desde un diagnóstico de intersexualidad o ADS". En E. Pérez Sedeño, E. Ortega (Eds.), Cartografías del cuerpo. Biopolíticas de la ciencia y la tecnología. Madrid: Cátedra.

Gregori, N.; Gallego, C.; García-Dauder, S. (2007). New management in intersex debates. Past, Present, Future: from Women's Studies to Post-Gender Research, Umea University, 14-17 June.

Halifax Resolutions (2009). Halifax Resolutions. 5th World Congress on Family Law and Children's Rights. Halifax (Canada). Recuperado de www.lawrights. asn.au/previous-congress/5th-worldcongress/76-halifax.pdf

Hart, S. (2009). World Athletics: Caster Semenya tests 'show high testosterone level. Recuperado de http://www.telegraph.co.uk/sport/othersports/athletics/6078171/World-Athletics-CasterSemenya-tests-show-high-testosterone-levels.html 
Hausman, B. (1998). "En busca de la subjetividad: transexualidad, medicina $y$ tecnologías de género". En J. A. Nieto (Comp.), Transexualidad, transgenerismo y cultura. Antropología, identidad y género (pp.193-233). Madrid: Talasa.

Herdt, G. (1990). “Mistaken gender: 5-alpha-reductase hermaphroditism and biological reductionism in sexual identity reconsidered". American Anthropologist, vol. 92, pp. 433-446.

Hines, M. (2004). "Psychological gender development in individuals born with ambiguous genitalia". En A. Balen, S. Creighton, M. C. Davies, J. MacDougall, R. Stanhope (Ed.), Paediatric and Adolescent Gynaecology. A Multidisciplinary Approach (pp. 492-508). Cambridge: Cambridge University Press.

Hines, M.; Ahmed, S. F.; Hughes, I. A. (2003). "Psychological outcomes and gender-related development in complete androgen insensitivity syndrome". Archives of Sexual Behaviour, vol. 32, no 2, pp. 93-101.

Hines, M. (2011). "Prenatal endocrine influences on sexual orientation and on sexually differentiated childhood behavior". Frontiers in Neuroendocrinology, vol. 32, no 2, pp. 170-82. DOI: 10.1016/j. yfrne.2011.02.006

Hinkle, C. E. (2006). Intersex. The right to one's self. Oll, Recuperado de www.intersexualite.org

Hurst, M. (2009). Semenya has male sex organs and no womb or ovaries. Recuperado de http://www.dailytelegraph.com. au/sport/semenya-has-no-womb-orovaries/story-e6frexni-1225771672245

Hutson, J. M.; Warne, G. L.; Grover, S. R. (2012). (Eds.). Disorders of Sex Development: An integrated approach to management. Verlag, Berlin, Heidelberg: Springer.

Karkazis, K.; Rossi, W. C. (2010). "Ethics for the Pediatrician. Disorders of Sex Development: Optimizing Care". Pediatrics in Review, vol. 31, no 11, pp. 82-85.

Kessler, S. (1998). Lessons from the Intersexed. New Jersey: Rutgers University Press.

Kim (sin apellido) (1999). "As is". En A. D. Dreger (Ed.), Intersex in the age of ethics (pp. 99-100). Maryland: University Publishing Group.

Kipnis, K.; Diamond, M. (1999). “Pediatric Ethics and the Surgical Assignement of Sex". En A. D. Dreger (Ed.), Inter- sex in the age of ethics (pp.119-137). Maryland: University Publishing Group.

Lee, P. A.; Houk C. P.; Ahmed S. F.; Hughes, I. A. and The International Consensus Conference on Intersex Working Group (2006). Consensus statement on management of intersex disorders. Pediatrics, vol. 118, no 2, pp. 488-500.

Laqueur, T. (1994). La construcción del sexo. Cuerpo y género desde los Griegos hasto Freud. Madrid: Cátedra (Feminismos).

López Siguero, J. P. (2008). Síndrome de insensibilidad androgénica. Recuperado de http://grapsia.org/images/eventos/2008/sia_jpls.pdf

Lucio, C. V.; Ábrego, V. (2003). "Hermafroditismo verdadero, características clínicas, genotipo e histología gonadal". Medicina Universitaria, vol. 5, no 20, pp. 176-179.

Marañón, G. (1928). “Nuevas ideas sobre el problema de la intersexualidad y sobre la cronología de los sexos". Revista de Occidente, vol. VI, no LXVI, pp. 257-294.

Marañón, G. (1930). La evolución de la sexualidad. Los estados intersexuales. Madrid: Morata.

Marca (2009). Semenya es hermafrodita. Recuperado de http://www. marca.com/2009/09/11/atletismo/1252661927.html

Martínez, M. (2005). “Mi cuerpo no es mío. Transexualidad masculina y presiones sociales de sexo". En GTQ (Grupo de Trabajo Queer), El eje del mal es heterosexual. Figuraciones, prácticas y movimientos feministas queer (pp. 113-121). Madrid: Traficantes de Sueños.

Martínez-Mora, J. (1994). Intersexual States. Disorders of Sex Differentiation. Barcelona: Doyma.

Martul, P. (2000). "Hipogonadismo: diagnóstico y tratamiento". Anales Españoles de Pediatría, vol. 52, no. 1, pp. 59-62.

Mazur, T. (2005). "Gender dysphoria and gender change in androgen insensitivity or micropenis". Archives of Sexual Behavior, vol. 34, pp. 411-421.

Meyer-Bahlburg H. F. (1999). “Gender assignment and reassignment in $46, \mathrm{XY}$ pseudohermaphroditism and related condition". The Journal of Clinical Endocrinoly and Metabolism, vol. 84, no 10, pp. 3455-3458.

Meyer-Bahlburg, H. F. (2005). "Gender identity outcome in female-raised 46 , $X Y$ persons with penile agenesis, cloacal exstrophy of the bladder, or penile abla- tion". Archives of Sexual Behavior, vol. 34, pp. 423-438.

Meyer-Bahlburg, H. F.; Gruen, R. S.; New, M. I. et al. (1996). "Gender change from female to male in classical congential adrenal hyperplasia". Hormones and Behaviour, vol. 30, no 4, pp. 19-32.

Money, J. (1973). Prenatal hormones and postnatal socialization in gender identity differentiation. Nebraska Symposium on Motivation, pp. 221-295.

Money J. (1975). "Ablatio penis: normal male infant sex-reassigned as a girl". Archives of Sexual Behaviour, vol. 4, pp. 65-71.

Money, J. (1976). "Gender identity and hermaphroditism [letter]". Science, vol. 191, no 4229, p. 872.

Money, J.; Ehrhardt, A. (1972). Man and Woman, Boy and Girl. Baltimore: Johns Hopkins University Press.

Money, J.; Hampson, J. G. y Hampson, J. L. (1955). "Hermaphroditism: Recommendations Concerning Assignment of Sex, Change of Sex, and Psychological Management". Bulletin of the John Hopkins Hospital, vol. 97, pp. 284-300.

Moreno, A. (1999). "In America they call us hermaphrodites". En A. D. Dreger (Ed.), Intersex in the age of ethics (pp. 137-140). Maryland: University Publishing Group.

Morris, S. G. (2006). "DSD and Identity". Archives of Disease in Childhood Online (Electronic Letter 22 August) Recuperado de http://adc.bmjjournals.com/cgi/ eletters $/ 91 / 7 / 554$

Nieto, J. A. (2003). "La intersexualidad y los límites del modelo 'dos sexos/dos géne-

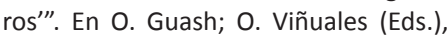
Sexualidades. Diversidad y control social (pp. 69-105). Barcelona: Bellaterra.

Parera, N. et al. (2001). "Manifestaciones clínicas de la pubertad en el varón y la mujer". En C. Buil; I. Lete; R. Ros; J.L. De Pablo (Coords.), Manual de salud reproductiva en la adolescencia. Aspectos básicos y clínicos (pp. 101-149). San Sebastián: Wyeth-Lederle.

Piro Biosca, C. (2002). "Estados intersexuales: tratamiento quirúrgico". En Sociedad Española de Endocrinología Pediátrica (Ed.), Estados intersexuales e hipogonadismo (pp. 129-140). Barcelona: J\&C Ediciones Médicas.

Preves, S. (1998). "For the Sake of the Children: Destigmatizing Intersexuality". The Journal of Clinical Ethics, vol. 9, no 4, pp. 411-418. 
Preves, S. (2003). Intersex and Identity. New Jersey and London: Rutgers University Press.

Puenzo, L. (2007). XXY. Argentina: Wanda Vision.

Reis, E. (2009). Bodies in Doubt. An American History of Intersex. Baltimore: The John Hopkins U.P.

Salamanca, A.; Nogales, F. (1998). "Hermafroditismo verdadero". En J. Botella; A. Fernández (Ed.), La evolución de la sexualidad y los estados intersexuales (pp. 271-279). Madrid: Díaz de Santos.

San Román, D. (2009). Habrá que disculparse ante la atleta, ante la federación y ante Sudáfrica. Recuperado de http://www.elmundo.es/elmundodeporte/2009/08/23/masdeporte/1251049697.html

Sánchez Planell, LI. (1994). "Psychopathological disorders in intersexual states". En J. Martínez-Mora (Comp.), Intersexual States. Disorders of Sex Differentiation (pp. 369-379). Barcelona: Doyma.

Simmonds, M. (2006). "Was Variations of Reproductive Development considered?". Archives of Disease in Childhood Online, Electronic Letter, 17 August. Recuperado de http://adc.bmjjournals. com/cgi/eletters/91/7/554.
Sytsma, S. (2006). Ethics and Intersex. Nederlands: Springer.

Tamar-Mattis, A. (2008). "Medical decisionmaking and the child with a DSD". Endocrine Today, November 2008.

Vázquez, F.; Moreno, A. (1995). "Un solo sexo. Invención de la monosexualidad y expulsión del hermafroditismo (España, siglos XV-XIX)". Daimon. Revista de Filosofía, no 11, pp. 95-112.

Vázquez, F.; Cleminson, R. (2010). "Subjectivities in transition: Gender and sexual identities in cases of 'sex change' and 'hermaphroditism' in Spain, c. 1500-1800". History of Science, $\mathrm{n}=48$ pp. 1-38.

Vázquez, F.; Cleminson, R. (2011). Los hermafroditas. Medicina e identidad sexual en España (1850-1960). Granada: Comares.

You Magazine (10 de septiembre de 2009). Wow, look al Caster now!. no 144, Cape Town, South Africa.

Wairimu Ngaruiya Njambi (2004). “Dualisms and female bodies in representations of African female circumcision: a feminist critique". Feminist Theory, vol. 5, no 3, pp. 281-303.

Williams, P.; Smith. M. (1980). Open Secret: The First Question. Science Series, BBC television production.
Wilson, J. D. (2001). "Androgens, androgen receptors, and male gender role behavior". Hormones and Behaviour, vol. 40, no 2, pp. 358-366

Wilson, B.; Reiner, W. (1998). "Management of Intersex: A Shifting Paradigm". The Journal of Clinical Ethics, vol. 9, no 4, pp. 360-370.

Wiesemann, C.; Ude-Koeller, S.; Sinnecker, G. H.; Thyen, U. (2009). "Ethical Principles and Recommendations for the Medical Management of Differences of Sex Development (DSD)/Intersex in Children and Adolescents". Pediatrics, vol. 671, pp. 674-76.

Wong, W. I.; Pasterski, V.; Hindmarsh, P.; Geffner, M. E.; Hines, M. (2013). "Are There Parental Socialization Effects on the Sex-Typed Behavior of Individuals with Congenital Adrenal Hyperplasia?". Archives of Sexual Behaviour, vol. 42, no 3, pp. 381-391.

Zucker, K. J. (1999). "Intersexuality and gender identity differentiation". Annual Review of Sex Research, vol. 10, pp. 1-69.

Zucker, K. J. (2005). "Measurement of Psychosexual Differentiation". Archives of Sexual Behavior, vol. 34, no 4, pp. 375388. DOI: 10.1007/s10508-005-4336-7 